\title{
Radicalising the marketing of higher education: learning from student- generated social media data
}

Dr Elvira Bolat ${ }^{1}$ and Ms Helen O’Sullivan ${ }^{2}$

${ }^{1}$ Corresponding Author, Faculty of Management, Bournemouth University, C113, Talbot Campus, Fern Barrow, Poole, BH12 5BB, E-mail: ebolat@bournemouth.ac.uk, Phone: 01202 968755

${ }^{2}$ Faculty of Management, Bournemouth University, C108, Talbot Campus, Fern Barrow, Poole, BH12 5BB, E-mail: hosullivan@bournemouth.ac.uk, Phone: 01202962205

\begin{abstract}
The social media landscape creates opportunities for higher education institutions (HEIs) to amplify psychological engagement with students and to increase influence impressions by following student(s)-to-student(s) conversations and stories. Evidence of understanding how HEIs can utilise student-generated social media data for HE marketing and branding purposes is underexplored. This paper adopts a netnographic research method to illustrate how social media artefacts, such as the ‘This Is Where I Study’ (TIWIS) Facebook page, created by students in the form of dialogues and content, can be analysed by HEIs to listen, engage further and influence students’ impressions. TIWIS illustrates that students’ engagement with social media platforms such as Facebook is dynamic in nature. It comprises behavioural expressions (manifestations and actions such as likes and shares as well opinion comments) and individuals' experiences (subjective in nature stories and comments of personal experiences and views). Hence, netnographic analysis allows capturing actual behaviours via longitudinal 'big data' sets and
\end{abstract}


support HEIs in proactive branding. Analysis of social media data demonstrates the value of encouraging and making accessible authentic conversations in order to create student-centred content.

Keywords: marketing of higher education; social media marketing; netnographic study; social media listening

\section{Introduction}

The Higher Education (HE) environment is experiencing a period of great change. Changes to student tuition fees, the de-regulation of student number controls, questions around contact hours and value for money, and trends towards large-scale marketisation and viewing the student as the consumer are to mention but a few (Tomlinson, 2015; Scullion and Molesworth, 2016). These changes have forced UK HEIs to search for a unique definition of what they offer in order to differentiate themselves and attract students (Chapleo, 2007; Hemsley-Brown and Goonawardana, 2007; Gai et al., 2016). Students are overloaded with sophisticated integrated marketing communications from universities, all promising to serve them better than the competition (Gai et al., 2016; Jan and Ammari, 2016). To maximise marketing opportunities, HEIs need to understand and commit to continuously listening to students' conversations, in which true stories and illustrations of students' relationships with HEIs are revealed (Tomlinson, 2015; Gai et al., 2016; Jan and Ammari, 2016). In doing so HEIs will optimise marketing impacts through business decisions that are based on student-consumers' data (He et al., 2015; Gai et al., 2016).

Tomlinson (2015) highlights that HEIs put less emphasis on understanding how students form their relationships with HEIs. HEIs are often forced to create their own digital footprint as well 
as to engage in practices similar to those in the tourism industry. These include reviewing usergenerated comments and content related to all aspects of the provision of HE experiential services (Scullion and Molesworth, 2016). This leaves us with the question of what aspects of HE experiences students talk about online, and what student-generated content could potentially be leveraged for effective HE branding.

Undoubtedly $21^{\text {st }}$ century students are active, digitally savvy choice-makers whose expectations, motives and experiences are socially constructed (Kandiko and Mawer, 2013). The social media landscape, therefore, creates opportunities for HEIs to amplify psychological engagement with students and to increase influence impressions by following student(s)-to-student(s) conversations and stories (Ashley and Tuten, 2015). Extensive studies on social media in the HE sector have been conducted (Ngai et al., 2015) with a primary focus on exploring the pedagogical value of social media in facilitating learning and supporting teaching practices (Dabbagh and Kitsanta, 2012; Neier and Zayer, 2015; Nel, 2015; Barn, 2016). Few studies (Jan and Ammari, 2016; Royo-Vela and Hünermund, 2016) looked into understanding how HEIs marketing efforts in online space via their own websites, search engine and social media optimisation, affect students' decision-making processes. Both studies found that content presented on HEIs' websites and their efforts to engage with social media leveraging have positive and significant impact on students' choices of HEIs. However, no in-depth evidence into understanding how students engage with social media content has been provided. Moreover, evidence of understanding how HEIs can utilise student-generated social media data for HE marketing and branding purposes is limited. Gai et al. (2016) conducted netnographic analysis of online content published within a Chinese online forum, dedicated to choosing international HEIs. However, to our knowledge no published study reports on experiences in listening and 
learning from Facebook student-generated social media data, as opposed to specialised in HE themes online forums as well as websites, blogs and microblogs developed for pedagogical purposes (Barn, 2016).

It is the consideration of the above-highlighted gaps and the need to illustrate how studentgenerated social media Facebook artefact can be used by HEIs for proactive marketing and branding that drives the rationale for this study. The aim of this study, therefore, is to illustrate a netnographic analysis of a 'This is Where I study' (TIWIS) Facebook page that can develop HE marketers' interest and continue academic conversations on role of netnographic data in HE marketing and pedagogical practices. Building on work by Calder et al. (2016), the research objective of this study is to explore actual student engagement (behaviour) with the studentgenerated HE experiences related content. The results of our analysis provide empirical evidence to illustrate that students' engagement with social media platforms such as Facebook is dynamic in nature. It comprises behavioural expressions (manifestations and actions such as likes and shares as well opinion comments) and individuals' experiences (subjective in nature stories and comments of personal experiences and views). Hence, netnographic analysis allows capturing actual behaviours via longitudinal 'big data' sets and support HEIs in proactive branding. Analysis of social media data demonstrates the value of encouraging and making accessible authentic conversations in order to create student-centred content.

This paper begins with a brief review of the literature relating to HE marketing, social media marketing and student experiences. The next section outlines the research method followed by a discussion of the findings. The study ends with the conclusions and overview of implications and limitations of this research. 


\section{Theoretical background}

HE has become one of the fastest-growing service sectors (Alwi and Kitchen, 2014). As discussed in the introductory section, recent changes in the HE context have forced UK HEIs to reconsider their operational and strategic models, integrating market-driven business practices to remain competitive and to maintain economic viability (Tomlinson, 2015; Scullion and Molesworth, 2016). The value and potential benefits of using marketing theories and concepts, which have been effective in the private sector, are now being applied by many HEIs in the attempt to gain competitive advantage (Hemsley-Brown and Oplatka, 2006; Jan and Ammari, 2016; Royo-Vela and Hünermund, 2016). It has even been suggested that 'higher education institutions need to be managed more and more as corporate brands' (Whelan and Wohlfeil, 2006, p. 317). One of the recent marketing developments in the business world involves effective leveraging of data and its analytics, which inform further business decisions (Chae, 2015). With the emergence of social media, individuals and consumers are documenting and sharing personal experiences as well as constructing full representation of self-identities via leaving social media footprints on the web (Correa et al., 2010). Moreover, Malthouse et al. (2016) suggest that brands and businesses should leverage social media opportunities by actively engaging in dialogue with consumers as well as allowing consumers to act as co-producers and co-creators of branded content. In particular Mathouse et al. (2016) analysed a big data set available from a Canadian coalition loyalty programme that recorded participation in promotional contests involving user-generated content (UGC) creation as well as ongoing purchase behavior. Longitudinal 'big data' set proved a positive correlation between engagement with UGC and actual purchasing behavior, meaning UGC was an effective way to drive the actual behavior. 
Research into electronic WOM (eWOM) and UGC's impact on consumers' behavior towards the brand is well developed. Chevalier and Mayzlin (2006) and earlier study (Godes and Mayzlin, 2004) found positive relationships between product reviews and consumers' choices and purchases of products. The study by Berger and Milkman (2012) discovered that within the UGC and online community contexts, it is mutually shared characteristics of content creator and consumer, which enable increased consumption of UGC. Hence, it should be argued that in the HE marketing context, content created by students is more likely to resonate with other students and result in higher engagement levels. The latest focus in the branded UGC consumption context is an understanding of how UGC should feed into brands' own storytelling and enable ‘open source’ branding (Fornier and Avery, 2011). Singh and Sonnenburg (2012) suggest brands that incorporate UGC topics and discussions into their own storytelling and branded content achieve higher social media engagement metrics for brand-created content. A study by Gensler $e t$ al. (2013) goes beyond empirical evidencing of relationships between UGC and effective brand storytelling but suggests that brands can engage in three types of strategies to manage UGC and relations with their social media public. Firstly, brands can listen carefully to comments and stories, and respond accordingly. Secondly, they can engage in the discussion of wider cultural issues by creating resonance. Last but not least, brands can 'attempt to leverage social media's connectedness and get consumers to play the brand's game by creating branded artifacts ... for consumers to appropriate and work on behalf of the brand' (Gensler et al., 2013, p. 253).

Despite social media being a vital part of current HE pedagogical practices, as argued by Gai et al. (2016) and Scullion and Molesworth (2016) the HE context is slower in recognising the value of student-generated social media data and content for the HE marketing, branding and recruitment purposes. Perhaps this is due to ethical dilemma of using authentic experiential 
stories for commercial purposes (Singh and Sonnenburg, 2012). Moreover, Scullion and Molesworth (2016) highlight conflicting practices of HEIs using social media spaces for pedagogical purposes where students gain digital literacy skills and are encouraged to experience freedom of creation, as opposed to using them for marketing purposes aimed at increasing HEIs’ student recruitment numbers.

Gai et al. (2016) conducted netnographic analysis of online content published within a Chinese online forum dedicated to choosing international HEIs. Although the online forum in Gai et al.'s (2016) study is an independent forum aimed at students sharing their international HE experiences and helping others to make more informed decisions, such forums have a specific theme that drives students to create and consume reviews and comments. It therefore limits authenticity and more dynamic understanding of students' experiences and engagement with HE products and services (Calder et al., 2016). Applying Gensler et al.'s (2013) framework of strategies, we suggest that brands need to monitor consumers' online brand-related activities and integrate UGC and discussions into their own branded stories. To meet the research aim of this study, we need to create a social media artifact that enables HE students to connect with each other and share experiences over time, and monitors the creation and consumption of HE brandrelated and experience-related content.

\section{Students as online consumers}

In 1997, UK scholars started to recognise students as consumers (Dearing, 1997). This has led to the emergence of the formally documented student-as-consumer approach, according to which students convey a consumer orientation in making choices about and experiencing HE services (Molesworth et al., 2011; Khanna et al., 2014; Hemsley-Brown and Oplatka, 2015; Bunce et al., 2016). A student-as-consumer approach, as with the latest developments in the consumer 
behaviour domain, proposes a shift of control and power from HEIs - the providers of services to students - the consumers of HE services and products (Tomlinson, 2015). Bunce et al. (2016) report a lack of empirical evidence suggesting that students are in fact seeing themselves as consumers while already experiencing HE services and products but do argue that at the stage of choosing HEIs students do act as consumers. Internet technology and applications play an even greater role in accelerating the power and control students-as-consumers are experiencing when engaging with HE services and products (Jan and Ammari, 2016; Royo-Vela and Hünermund, 2016). Students-as-consumers are accessing data, making decisions and sharing their stories about their educational experiences online, revealing traits of so-called 'online consumers' (Racolta-Paina and Luca, 2010, Akar and Nasir, 2015). Effectively, the intangible nature of HE services and products force students to turn to the internet and social media sharing platforms for authentic insights into current student-as-consumer experiences. So far the vast majority of existing research (Molesworth et al., 2009; Williams, 2013; Woodall et al., 2014) looks into understanding the educational demands and challenges of the student-as-consumer approach, rather than investigating and profiling the students as consumers, in particular from the online consumer perspective.

Nevertheless, there are two studies (Jan and Ammari, 2016; Royo-Vela and Hünermund, 2016) that looked into understanding how HEIs marketing efforts in online space via their own websites, search engine and social media optimisation, affect students' decision-making process. Jan and Ammari (2016), using structural equation modeling, tested and found the positive impact of HEI-generated social media, website and display advertising content on student choices in Malaysia. The research found HEIs' websites to be most influential in confirming students' choices. Royo-Vela and Hünermund (2016) conducted qualitative in-depth study into 
understanding what online channels have significant impact on postgraduate students' choice of HEIs. They found that students do rely heavily on advertising, university ranking websites and previous experiences, mostly documented via social media sites. However, it provided no deep understanding on how students engage with social media HE branded content.

To date, characteristics of students as online consumers of HE experiences remain neglected or are assumed to be similar to online consumers of younger age groups. Scullion and Molesworth (2016) call scholars to investigate the student-as-consumer phenomenon in greater detail by recognising student-consumers' distinctive values, needs and behaviours. Following online consumption literature around eWOM and UGC, we can assume that students as online consumers could be categorised into three distinct groups. Firstly, there are students as online content consumers for pedagogical and/or personal HE experience purposes. Secondly, there are students as online content contributors for pedagogical and/or personal HE experience purposes, and finally there are students as online content creators for pedagogical and personal HE experience purposes (Muntinga et al., 2011). Pedagogic literature does discuss in great details students' engagement with social media across three types of behavior (consumer (e.g. Veletsianos et al., 2015); contributor (e.g. Barczyk and Duncan, 2013); creator (e.g. Barns, 2016)). It is, therefore, rational to explore in greater depth students as online consumers of HE experiences for personal purposes. It is best to start with investigating students' engagement with social media content related to HE experiences and brands.

Engagement represents a complex construct of comprising cognitive, behavioural and emotional experiences (Calder et al., 2016). However, when it comes to engagement in digital environments Calder et al. (2016) call for new evidences of context-specific netnographic studies that can capture individuals' behavioural expressions and individuals' experiences. Individuals' 
behavioural expressions represent manifestations and actions such as likes and shares as well opinion comments - interaction and activity metrics of social media engagement as suggested by Tuten and Solomon (2014). Individuals' experiences represent subjective in nature stories and comments of personal experiences and views which can be analysed via sentiment analysis. Hence, Calder et al.' (2016) conceptualisation of engagement as a dynamic iterative exchange between behavioural expressions and experiences can help to achieve the research objective of this study. Figure 1 shows conceptualisation of student as online consumer engagement with student-generated Facebook content, related to HE experiences that will be explored in this study. 
Figure 1. Conceptualisation of engagement with student-generated Facebook content

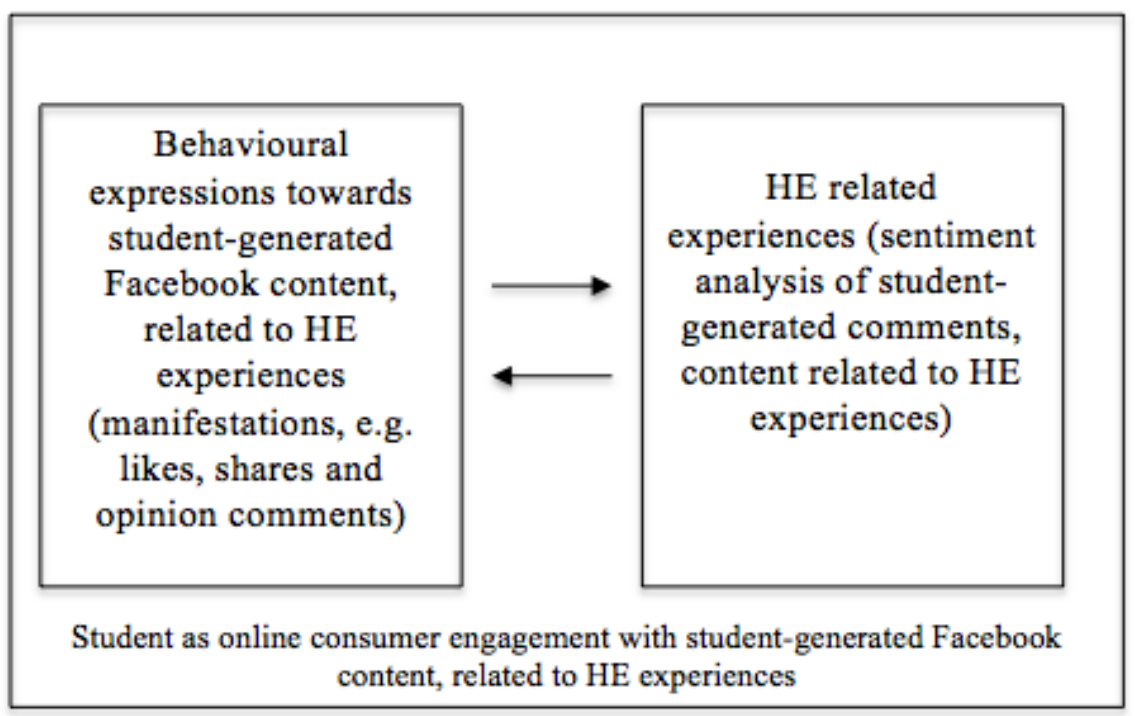


Social media and its application in the HE context

Social media, defined as technological platforms and channels which enable communication and exchange of data virtually between individuals or groups of individuals anywhere anytime (Kaplan and Haenlein, 2010; Kietzmann et al., 2011), are paramount to brands and businesses connecting and interacting with their consumers (Murdough, 2009). So far, social media use in the context of education has been investigated with a focus on the pedagogical power of social media in enabling collaborative learning (Hussain, 2012; Deng and Tavares, 2013). Another interesting topic on the current agenda of HE pedagogy and HE marketing scholars is the impact social media plays in students' engagement with HE with specific reference to the fear of missing out (FoMo) (Hetz et al., 2015; Vorderer et al., 2016). These studies conclude that while engaging with $\mathrm{HE}$, students tend to consume social media content and communicate with their peers and networks beyond learning purposes, which overall results in distractions from the learning process. However, an important fact to note from these FoMo studies is that students are active social media users who follow other students' HE experiences as well as share their own authentic stories because they simply do not want to miss out on important conversations, life changing opportunities and evidence that can drastically impact on their decisions.

Despite numerous attempts to integrate social media in the delivery of HE, it has been already stated that its use for branding and marketing purposes is under explored by the HEIs (Gai et al., 2016). Although marketisation is not new to the HE context, HEI marketers need to accept that the modern brand communication landscape has changed significantly (Whelan and Wohlfeil, 2006) and adopt wider business practices of using social media to protect and expand the brand, monitor customer interactions, share and encourage positive brand, product or service engagement. As suggested by Gensler et al.'s (2013) and applying Calder et al.' (2016) 
conceptualisation of engagement, HEIs could use student-generated to understand the actual behavior and experiences of students, as well as to tap into stories of behavioral expressions and experiences to engage in 'open source' branding practices.

\section{Method}

Due to the exploratory nature of this study's aim, a qualitative approach has been adopted (Creswell, 2007). Student-generated HE related conversations about experiencing HE cannot be detached from the social media environment that enables and influences the process, tone and outcomes of social media conversations (Gai et al., 2016). This study employed a netnographic research method to conduct an ethnographic analysis of interactions of students within an online community (Kozinets, 2015). Applying Calder et al.’s (2016) conceptualisation of engagement construct, we have examined netnographic subjects (students communicating within an online community) and their interactions, with the purpose of extracting netnographic evidences of behavioural expressions and experiences of student-generated Facebook content, related to HE experiences.

Student-generated data was collected using the social media artefact the TIWIS Facebook page: https://www.facebook.com/This-Is-Where-I-Study-351708698330262/. TIWIS represents the UK HE experiences consociation with a common theme for users and audience. In the chosen context and theme, TIWIS aims to integrate all four types of online experience proposed by Kozinets (2015), namely mingling, sharing, bonding and organising in relation to a common theme - HE-related experiences. TIWIS differs from HEIs’ own social media communities as its purpose is to feature student-generated content created and shared by students for students. Having a single case limits the reliability of the results and the extent to which they can be 
generalised, but when dealing with complex phenomenon and context (i.e. social media interactions and connections) it allows a deeper understanding of conversations and user engagement. Moreover, the focus on a single social media artefact assists in the sampling process by framing contextual boundaries and, hence, a better interpretation of results (Gai et al., 2016).

The netnographic research context - TIWIS

TIWIS stands for 'This Is Where I Study', which is a Bournemouth University (BU)-led collaborative journalism and marketing project. TIWIS is essentially a 'social journalism' artefact that caters for international students seeking to study in UK universities. TIWIS utilised the social media and marketing expertise of Bournemouth University journalism and marketing staff and students to produce reportage that prospective foreign students can draw from. Anecdotal evidence in recent years identifies a gap: while there is plenty of 'official' information about UK universities, this does not always answer some fundamental questions. TIWIS has helped remedy this by allowing for a student-led production—essentially, encouraging students to create the kind of content they want. International students also highlight the value they place on 'word of mouth'. TIWIS addressed this by creating a dedicated place for relevant 'social recommendations' on aspects of HE/student life that is easily accessible and, importantly, socially shareable. BU students worked with teams from other UK HEIs for content production. The BU journalism team was drawn from MA Multimedia Journalism students, with the marketing team drawn from MSc Marketing Management students. The ultimate intention of the TIWIS project was to create student-related and relevant content with the intention of stimulating continuous students' conversations which would firstly benefit and improve experiences of international students studying in the UK and secondly enable the generation of student- 
generated data that can be analysed and underpin the UK HEIs' marketing initiatives as well as other business decisions.

The TIWIS Facebook page is a focal point of conversations among international students looking to study, or currently studying, in the UK. Hence, TIWIS represents a 'perfect' focal context for the netnographic inquiry set to explore students' engagement with student-created content, related to HE experiences. Facebook is undoubtedly the most popular and widely used social media site. Facebook’s technical capabilities enable users to create personal (personal accounts), social (groups and pages) and professional (brand and community pages) spaces. To date Facebook has over 1.35 billion users, making it the most populated social media site. Facebook users share, create and consume content in various formats, such as text, images, videos and audio including live-streamed audio, video and textual conversations (Smith et al., 2011). RoyoVela and Hünermund (2016) found that Facebook and Google+ are main social media platforms to access trustworthy information regarding HE experiences. As a result, TIWIS is well-suited to Facebook which, given its popularity and usage statistics worldwide, will maximise reach for the student-generated social media content. In further sections, we explain how TIWIS was set up as well as detail of netnographic data analysis carried out in this study.

Pre-netnographic phase: TIWIS setup and unit of analysis

Facebook metadata represents the main unit of analysis in this study. Data includes Facebook posts from $4^{\text {th }}$ March 2015 to $4^{\text {th }}$ July 2016, with images representing the main format of posts/content for the TIWIS team of students. Images/photos are known best to provoke further conversations and stimulate users to generate and share own content (Strekalova and Krieger, 2015) and in the case of TIWIS images triggered conversations, content creation and sharing among the TIWIS fan base. Each image is also accompanied by a short article/story, written by 
journalism students. Some of the articles may link to other websites or external content, selected and posted by students content creators (journalism students) and content contributors (marketing students).

Photo albums represented collections of different themes/areas of interest for the target audience: international students studying in the UK. These themes derived from the TIWIS setup research phase. The TIWIS setup research phase included a thematic analysis of secondary and primary data, which comprised interviews and focus groups with international students as well as social media analytics of popular among international students web search terms. Social media analytics involved the use of social media monitoring and analysis tool Alexa and native platform-specific search analytics across the following social media platforms, YouTube, LinkedIn, Twitter, Instagram and Facebook. The aim of the TIWIS setup research phase was to understand what types of content would be particularly interesting for students experiencing HE in general, as well as students who study outside home country. In particular, two focus groups were carried out with international students studying at Bournemouth University. Both focus groups involved six participants and represented mixed gender, mixed age range and mixed nationalities. Twelve interviews, lasting for up to twenty minutes each, with nine international and three UK students studying at Bournemouth University were carried out to confirm the data derived from the focus groups. Table 1 presents a full profile of focus groups and interview participants. 
Table 1. TIWIS setup phase: focus group and interview participant's profile

\begin{tabular}{|c|c|}
\hline Focus group participants & Interview participants* \\
\hline Focus group 1: & Sami - female, Thailand, postgraduate course \\
\hline 1.1 Female, 18-24, Taiwan & Elena - female, Greece, undergraduate course \\
\hline 1.2 Female, 18-24, Vietnam & Maksim - male, Russia, postgraduate course \\
\hline 1.3 Female, 25-31, Taiwan & Jonny - male, China, undergraduate course \\
\hline 1.4 Male, 18-24, Nigeria & Anna - female, Norway, postgraduate course \\
\hline 1.5 Male, 25-31, Turkey & Lena - female, Venezuela, postgraduate course \\
\hline 1.6 Male, 18-24, Russia & Joy - female, Taiwan, postgraduate course \\
\hline Focus group 2: & Bianca - female, Poland, undergraduate course \\
\hline 2.1 Female, 25-31, Ukraine & Karl - male, Norway, postgraduate course \\
\hline 2.2 Female, 25-31, Spain & Ozi - male, UK, undergraduate course \\
\hline 2.3 Female, 18-24, Columbia & Chloe - female, UK, postgraduate course \\
\hline 2.4 Male, 18-24, China & Hannah - female, UK, undergraduate course \\
\hline 2.5 Male, 18-24, China & \\
\hline 2.6 Male, $18-24$, Thailand & \\
\hline
\end{tabular}

Note: All names are anonymised using pseudonyms 
Qualitative primary data was entered into NVivo 10, qualitative data analysis software, and analysed using thematic analysis focusing on themes with intention to explore social media content of interest among international students studying in the UK HEIs. Iterative process of coding and themes identification was applied to, firstly, identify initial themes emerging from primary data and, secondly, to compare primary data themes against secondary data themes and to corroborate the coded themes (Fereday and Muir-Cochrane, 2006).

The following themes were identified:

- Tales from Britain - collates tales of studentship in Great Britain: What is it to live here? How is it to study? What is expected of you? Voices from across the UK.

An extract from the interview with Sami (postgraduate female student) reinforced the need for content in this theme:

Before coming to England, I was feeling anxious and was in need of information about life in the UK. I was hungry for real examples and stories from similar to me students.... For example I was not aware that buying fish cheaply could be a problem. I wish someone could make me aware and also recommend places where I could buy quality fish for reasonable price.

- Best 4 places to go for a coffee on a cold day: Tips for best places to visit in terrible rainy British weather.

An extract from the interview with Elena (undergraduate female student) illustrates a view that was shared by all interviewees and focus group participants, including UK-based students: 
Oh God, weather is buzzword when it comes to England. You can be prepared by buying pair of wellies and raincoat. But when you are here, you kind of lost in what to do and having that advise can help you see rain as fun enabler.

- Fantastic places: places to be visited around the UK.

This theme was first to be discussed by both focus group participants who wanted "to plan ahead” their UK experience and learn about visiting “interesting exciting places”.

- Scholarships: intended for prospective students who would like to learn about obtaining and applying for scholarships.

This topic was mentioned by six interviewees and was part of both focus group discussions. It mainly covered the pre-arrival period as well as the desire of some students to share their own experiences of successfully securing scholarship. A student from Russia stated:

Everyone in Russia now is looking for discounts and scholarships. I did get one and helping others to learn about my experience will be good way of supporting my fellows.

Moreover, secondary analysis of keywords and hashtags using Google Ad Words, Twitter and Facebook hashtag search, and hashtag analysis portal hashtag.org, demonstrated that scholarships were main search terms among students.

- Specific university-branded content: overview of the UK HEIs as well as experiential stories of students. 
All focus groups and interviewed students agreed that once they have chosen an HEI and are in the UK, they seek more stories about experiences and opportunities which are posted and created by students like them. Jonny (an undergraduate student from China) stated:

There are websites I have used to learn about my university and I do follow Twitter account of my university, but I want something more real. I mean I wanted to hear from students like me. Hear about best place for self-study or perhaps advise on someone who does personal training sessions with me.

The first images within each of the four themed albums were piloted with participated in focus groups students. These were intended to confirm that the content represented the theme well. Each TIWIS image within a theme-based album is accompanied by a short story that reflects the essence of the image and allows students to engage with topics beyond selected themes - to name a few, food, social life, love, learning, and friendships. Later in the timeframe (after August 2015), some stories were presented using video rather than images. Again, both journalism and marketing students participated in the decision-making process on what content to extend and produce in video.

Finally, qualitative interviews with four students involved in creating TIWIS content, as well with two educators co-ordinating and supporting those students, allowed reflection on the experiences of students and educators involved in creating and maintaining of the Facebook artefact. These reflective interviews lasted for up to thirty minutes and were analysed using thematic analysis. NVivo 10 assisted in the coding and analysis process. Analysis and interpretation of this data is presented in the beginning of the findings section. 
Netnographic data analysis and research ethics

For analysis purposes the following data was included: likes, shares, comments of TIWIS fans as well as Facebook analytics for engagement and activities and performance of the TIWIS Facebook page. A mixed method analysis was performed with qualitative data analysis focused on the content of posts as well as impressions in the form of text-based comments and quantitative analysis reflecting on frequencies and quantitative interaction metrics adopted from Tuten and Solomon (2014). Once qualitative data had been categorised into types of posts, its analysis involved the inductive coding of text-based elements, activities and interactions. Two researchers coded text-based elements simultaneously and completed the qualitative data analysis with a joint discussion/agreement on the final list of generated themes. Based on the types of data generated by Facebook, in line with the netnography method the following three analytical steps were performed (adapted from Chae (2015)):

1. Descriptive analysis - Facebook data contains a large amount of information, including metadata (e.g., information on page fans) and posts, all of which are descriptive in nature, to name a few: number of posts, types of content, distribution of different types of content, number of hashtags.

2. Sentiment analysis - Facebook enables social dialogues and commentary using not only reaction and engagement-measuring tools (i.e. likes, shares etc.) but also using written communication and emoji symbols which are capturing the essence of social media conversations as well as representing the richest data (Debatin et al., 2009). Hence, qualitative data mining is critical to extracting relevant and important data. This data was extracted and imported into NVivo 10 to perform sentiment analysis. Sentiment analysis aims to determine opinions and polarity of opinions by text mining and categorising 
portions of the text documents to differentiate these phrases and sentences that communicate positive, negative or neutral in nature meanings (Pang and Lee, 2008). NVivo 10 for Windows has sentiment analysis query function.

3. Network analysis - due to the various formats of data sharable via Facebook, there are also various ways to measure engagement with the content as well as among fans/users, i.e. post reach, page reach, number of likes, number of shares, post clicks.

Moreover, to fulfill the research objective of this study, netnographic analysis involved the empirical exploration of the conceptualisation of engagement proposed in the theoretical background section. In particular, behavioural expressions were studied via descriptive and network analysis. Experiences were studied using sentiment analysis.

Given that netnography is continuously evolving methodology (Oakes et al., 2013), ethical aspects of obtaining consent and observing data in a public domain are challenging to address. This study has completed an ethical committee review on institutional level and can be considered as a combination of observational and action-based netnography (Kozinets, 2015). We fully disclosed the purpose of the study and roles of the academic researchers to all students participating in a content creation and contribution, interviewees and focus groups participants. Moreover, we announced the purpose of the project to the TIWIS page fans under 'About' tab. Nevertheless, this study involved elements of observational netnography because throughout the research process we did not continuously seek observation permission to avoid intervention in interactions between the TIWIS fans. According to Lager and Beckman (2005) disclosure of a researcher's presence to an online community members can limit authenticity in members' participation and discussions. Observed netnographic, interview and focus group data have been kept confidential and anonymous by using pseudonyms. In this study we do not present direct 
quotes or textual data from Facebook fans' comments. In relation to fans-related data, in this study we only present analytics data around engagement and overall conclusions on sentiment analysis of commentary posts. The findings are discussed below.

\section{Findings and discussion}

\section{TIWIS as a social journalism project}

The TIWIS Facebook page itself is the primary platform for the dissemination of the content, given its value to the 300,000-plus international students looking at the UK. To date, the page has attracted more than 20,000 likes. Table 2 presents the list of the types of posts. Majority of posts (70 per cent) contain photos/images and only 15 per cent of posts were in a video format. Forty-six per cent of all TIWIS posts contain links to external sources. Only three per cent of TIWIS posts contain announcements related to scholarship application deadlines or invitation to a particular event. Twenty-one per cent of posts involved commentary conversations so included commentary posts, whereas only five per cent of all TIWIS posts led to separate conversations using 'Chat' messaging function on Facebook. All of these chats were in a form of one-to-one interaction between a TIWIS fan and the TIWIS admin team. 
Table 2. Types of posts on TIWIS

\begin{tabular}{|l|l|l|l|l|l|}
\hline $\begin{array}{l}\text { Conversational } \\
\text { posts }\end{array}$ & $\begin{array}{l}\text { Announcement } \\
\text { posts }\end{array}$ & $\begin{array}{l}\text { Links to } \\
\text { external } \\
\text { content }\end{array}$ & Photo/image & Video & Chat \\
\hline $21 \%$ & $3 \%$ & $46 \%$ & $70 \%$ & $15 \%$ & $5 \%$ \\
\hline
\end{tabular}


Students from BU and collaborating HEIs involved in the creation of stories and posts report that involvement with TIWIS led to the enhanced learning of UK and HEI experiences in two ways. Firstly, it has provided experiential and work-based learning for journalism and marketing students. Secondly, it has led to an enhanced international students' experience as - due to FoMo - students were encouraged to expand their experiences and involvement with HEIs and the UK overall. Students were determined to create relevant content, and developed critical thinking skills in the process. This is in line with educational literature around UGC (Muntinga et al., 2011; Barczyk and Duncan, 2013; Veletsianos et al., 2015; Barns, 2016). Two of the students who created and curated content stressed:

Talking to other students about their university experiences, capturing common topics and then seeing reaction of the audience just triggered a drive in me to create more and see reaction of the crowd, their comments. [JSBU]

Reading created stories made me realise how much I have been missing out. Since then I visited Oxford for the first time and fully explored the town I live in. Strange! But this process made me fully react to stories. I acted as intermediary between journalist students and audience, deciding on what content should be published but in actual fact I was choosing content that made me act. [MSBU]

From the educators' perspective, TIWIS enabled professional development, which included both learning about different teaching approaches and engaging with new media technologies. Educator1 stated:

Seeing process of students generating content and translating it to audience with the use of latest social media features that increase engagement, e.g. 360 degree videos or 
timeline videos, is an amazing insight into new possibilities to present my teaching content differently. Perhaps that could really improve student engagement in my class.

Secondly, it provided opportunities to engage and listen to student-generated stories and studentto-students conversations that indicate students' interests as well illustrate students' engagement and experiences with HE. Educators 2 highlighted:

Most of content that is of interest to international students studying in the UK universities does not concern teaching and learning. However, reading through content and comments I realised how much all these resources, we - academics often consider irrelevant to pedagogic processes, are important to emotional stability of students and overall engagement with learning too.

In the corporate literature, creative strategy encompasses message content and message strategies in the notion of designed communications, which increase the likelihood of enhancing consumer engagement or achieving the desired financial performance (Ashely and Tuten, 2015). TIWIS demonstrates that student/consumer-generated data needs to underpin the creative strategies of HEIs' marketing programmes as well as pedagogic practices. This is because student-to-student conversations, as well as student-generated posts, directly communicate students-as-consumers' aspirations, experiences, feelings and emotions, meaning that by tapping into student-to-student conversations HE marketers can match the HEI brand's messages to the students' needs and desires.

Understanding nature of and engagement with the student-generated data: three-step analysis Table 3 illustrates the main results of student-generated social media metrics with a particular emphasis on findings that have implications for the marketing of HE. 
Table 3. Results of three-step social media data analysis

\begin{tabular}{|c|c|c|}
\hline $\begin{array}{c}\text { Type of Data } \\
\text { Analysis }\end{array}$ & TIWIS metadata & $\begin{array}{l}\text { Implications for the HE } \\
\text { marketing }\end{array}$ \\
\hline \multirow{3}{*}{$\begin{array}{l}\text { I. Descriptive } \\
\text { analysis - } \\
\text { behavioural } \\
\text { expressions }\end{array}$} & $\begin{array}{l}\text { Images - average reach }=1,042 \text { with on } \\
\text { average } 85 \text { clicks per image and } 19 \\
\text { comments per image post }\end{array}$ & \multirow{3}{*}{$\begin{array}{l}\text { Images are the most popular } \\
\text { type of content, which enable } \\
\text { further commentary, interaction, } \\
\text { and engagement with various } \\
\text { themes. Hence, HEIs' social } \\
\text { media content is best to utilise } \\
\text { image formats. }\end{array}$} \\
\hline & $\begin{array}{l}\text { Videos - average reach }=567 \text { with on } \\
\text { average } 17 \text { clicks and } 7 \text { comments per } \\
\text { video post }\end{array}$ & \\
\hline & $\begin{array}{l}\text { Written posts - average reach }=327 \text { on } \\
\text { average per post and } 7 \text { clicks and } 1 \\
\text { comment on average per post }\end{array}$ & \\
\hline $\begin{array}{l}\text { II. Sentiment } \\
\text { analysis - HE } \\
\text { related } \\
\text { experiences }\end{array}$ & $\begin{array}{l}\text { Main popular themes and conversations } \\
\text { based on analysis of posts with the } \\
\text { highest reach (based on correlation } \\
\text { between likes and clicks): } \\
\text { Cultural differences in learning } \\
\text { approaches - sentiment ratio is 5:1 (five } \\
\text { positive comments versus one negative) } \\
\text { Cultural differences in lifestyle - } \\
\text { sentiment ration is 1:1 (one positive } \\
\text { comment versus one negative) } \\
\text { Extra-curricular activities, i.e. sport, art, } \\
\text { etc. - sentiment ration is 7:1 (seven } \\
\text { positive comments versus one negative) }\end{array}$ & $\begin{array}{l}\text { Cultural differences are } \\
\text { highlighted as the main subject } \\
\text { of conversations among } \\
\text { international students, which } \\
\text { primarily indicate an interest in } \\
\text { the UK culture, unpleasant } \\
\text { experiences with discovering } \\
\text { differences as well as } \\
\text { understanding what can be } \\
\text { experienced beyond teaching } \\
\text { and learning context. Overall } \\
\text { analysis indicates important } \\
\text { messages for those promoting } \\
\text { and marketing the UK HE to } \\
\text { international students - the need } \\
\text { to portray the UK learning } \\
\text { experience as a journey which }\end{array}$ \\
\hline
\end{tabular}




\begin{tabular}{|c|c|c|}
\hline & & $\begin{array}{l}\text { integrates all aspects of } \\
\text { students’ lives, social, learning } \\
\text { etc. Students are clearly making } \\
\text { choices beyond a simple focus } \\
\text { on subjects and reputation of } \\
\text { individual HEIs. Sentiment } \\
\text { analysis across popular themes } \\
\text { indicates that overall UK HE } \\
\text { experiences are way more } \\
\text { positive than negative. }\end{array}$ \\
\hline \multirow{3}{*}{$\begin{array}{l}\text { III. Network } \\
\text { analysis - } \\
\text { behavioural } \\
\text { expressions and } \\
\text { connections' } \\
\text { characteristics }\end{array}$} & $\begin{array}{l}\text { Men vs woman }=77 \% \text { of fans vs } 23 \% \\
\text { of fans; however, women are more } \\
\text { inclined to comment and share the } \\
\text { content ( } 10 \% \text { higher than men) }\end{array}$ & \multirow{3}{*}{$\begin{array}{l}\text { It is important to create social } \\
\text { media marketing content, which } \\
\text { encourages shares to enable } \\
\text { eWOM and further engagement } \\
\text { with the content. This is due to } \\
\text { social media being effective in } \\
\text { maximising psychological } \\
\text { engagement with prospective } \\
\text { students who would be better } \\
\text { understanding motives, needs } \\
\text { and goals linked with HE from } \\
\text { current students. }\end{array}$} \\
\hline & $\begin{array}{l}\text { Average age group of fans - 18-24 with } \\
46 \% \text { of them liking the page (becoming } \\
\text { the fan) based on content shared via } \\
\text { their social circle of Facebook friends }\end{array}$ & \\
\hline & $\begin{array}{l}\text { Most fans engage with the post via } \\
\text { means of likes ( } 54 \text { per post on average), } \\
\text { followed by shares and comments (for } \\
\text { both } 3 \text { on average per post). }\end{array}$ & \\
\hline
\end{tabular}


Table 3 illustrates that students engaged well with student-generated content across different types of format. Images were found particularly popular and triggered further comments and interactions. It is important to note that sentiment analysis of commentary content suggest that behavioural expressions through likes and shares do in fact affect the experiences of students consuming the content. This corresponds with existing research on engagement (Brodie et al., 2011; Calder et al., 2016). Hence, results of descriptive and sentiment analysis confirm that behavioural expressions affect HE related experiences presented in Figure 1.

Sentiment analysis highlights that although students seek to consume content across the themes identified during the TIWIS setup research process, reactions and commentaries to content generated by students-creators reveal truly important themes comprising international students' HE experiences. Sentiment analysis overall demonstrates that students react positively to student-generated content and that HE experience is a complex system of various elements, which in the case of international student includes aspects of culture and social norms. Most commentaries have not triggered further behavioural expressions of likes, so in this section of analysis we have not found evidence to demonstrate impact of HE related experiences on behavioural expressions towards student-generated TIWIS content, related to HE experiences.

In line with existing studies around online consumers and their behaviour (Punj, 2011; Adnan, 2014; Clemes et al., 2014; Vaidehi, 2014) descriptive and network analysis suggests that male users are more engaged with social media in terms of demonstrating their one off token of appreciation, liking the page and hence becoming a fan. However, female TIWIS fans are much more engaged on a deeper level as they tend to disseminate the content to their friendship circles as well as act as commentators rather than simply observing the content. Network analysis extends further results of sentiment analysis showing that in the case of TIWIS, female students 
are more likely to provide insights into own experiences of HE, meaning in female students behavioural expressions trigger sharing their own HE-related experiences. Further contextualised and survey-based studies are required to evaluate the extent to which this evidence can be generalised. As with previous studies on social media engagement (Doorn et al., 2010) network analysis of TIWIS found that students' engagement with social media posts and content is behaviour-based, such as sharing, participating by commenting, and actively creating generated content. According to Ashely and Tuten (2015) these behaviours serve as a purpose to form positive word-of-mouth and TIWIS analysis supports this argument as posts achieving more likes and comments are shared more frequently than less liked posts and content.

Interpretation of three-step social media data analysis suggests a number of implications for HE marketing. The TIWIS Facebook page illustrates how in practice HEIs can learn from the student-generated social media content by performing a three-step analysis of social media data. The most important implication for HE marketers to leverage student-generated social media data is maximising psychological engagement with HE-related experiences and hence increasing influence impressions. However, in doing so HEIs, following experiences of market-driven businesses, need to collaborate with student (brand) personas who can endorse their positive HE experiences in an authentic way and, therefore increase social impressions. Learning from TIWIS, social endorsement can also have a group-based collaborative partnership where HEIs can collaborate with students with the intention of creating similar artefacts. In such a manner, HEIs ensure access to the content as well as enabling collaborative work-based learning for students who organise, participate and lead the management, distribution and creation of content.

Interactivity distinguishes contemporary social media from conventional mass media by expanding conversational contexts and enabling a virtual bond/friendship among users (Eveland, 
2003). Consumers consume social media content in order to socially interact and meet people with similar interests (Ko et al., 2005). Whiting and Williams (2013) report that 88 per cent of social media users benefit from the interaction capabilities of social media platforms. Hence, it is not surprising to find that most students looking for HEIs or currently studying in HE are forming social media groups and networks with the purpose of discussing and sharing HE experiences. In this study the TIWIS Facebook page unites prospective and current international students studying in UK HEIs.

Mangold and Faulds (2009) and Hanna et al. (2011) both proposed that social media should be considered as a hybrid element and included into a businesses' integrated marketing communications strategy due to containing the most influential but challenging to manage outcome of marketing communications - word-of-mouth. The TIWIS case demonstrates that female users are most likely to enable word-of-mouth and, hence, increase reach of Facebook posts and messages.

Moreover amplified word-of-mouth is the result of the increased psychological engagement with authentic content generated by students for students. Sentiment analysis results suggest that when choosing HEIs, international students focus on the overall aspects of students' lives, where social and learning experiences are intertwined. The subjects delivered by, and the reputation of, individual HEIs are not of significant importance to students-as-consumers. The only way to portray students' lives is to use authentic student-generated data. In the context of corporate brands people increasingly choose brands that are perceived authentic and more genuine than their competitors (Faust Householder, 2009). An authentic brand is a 'brand with a real story, a connection to a fundamental human truth' (Faust and Householder, 2009, pp.47). The central challenge of social media lies in creating something that is both engaging for consumers, but also 
stays true to the core of the brand. This proves that creating authentic student stories needs to be implemented simultaneously with listening to students’ reactions and conversations.

Social media has changed the way businesses communicate with their customers by fundamentally influencing customers' awareness, information acquisition practices, attitudes towards the product, purchasing and post-purchasing behaviour (Mangold and Faulds, 2009). Despite the fact that TIWIS analysis does not allow us to conclude whether this is the case in the HE context, in particular with the effect on attitudes, consumption and post-consumption of HE services and products; TIWIS comments and conversations demonstrate that social media generates awareness as it acts as a bank of HE-related experiences and stories. Moreover, the TIWIS case demonstrates that student as online consumer engagement with student-generated Facebook content, related to $\mathrm{HE}$ experiences, is a dynamic construct where behavioural expressions affect HE related experiences, but not vice versa. Hence, engagement with studentgenerated TIWIS Facebook page content can be conceptualised as per Figure 2. This conceptualisation needs further evidence in empirical studies similar to this as well as further examination of relationships between such engagement construct and choices of HE students. 
Figure 2. Conceptualisation of engagement with student-generated TIWIS content

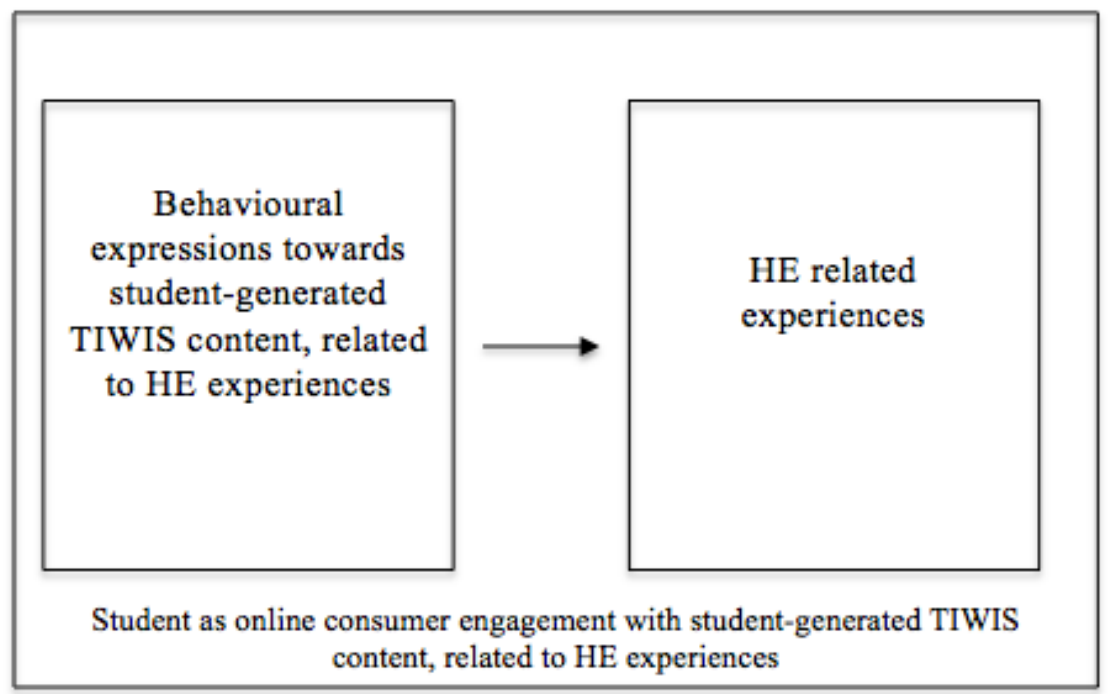




\section{Conclusion and implications}

The netnographic analysis of TIWIS illustrates that students do engage well with studentgenerated content, manifesting behavioural expressions that impact on the experiences of students consuming content. This finding, however, requires further empirical investigation in HE and other contexts. Having one artefact analysed in this study within the context of international students' HE related experiences is the main limitation of this study, which calls for further research applying similar methodology or conceptualisation of engagement.

Moreover, netnographic analysis performed in this study demonstrates how in practice HEIs can learn from the student-generated social media content by performing a three-step analysis of social media data. As discussed in the previous section, the most important implication for HE marketers to leverage student-generated social media data is maximising psychological engagement with HE related experiences and hence increasing influence impressions. Clearly, social listening needs to be embedded into social media marketing practices of HE.

Furthermore, the brand is an important element in marketing and it is perceived to be true in the context of HE. Marketers often categorise social media as a branding channel. The perceived benefits of branded social media activities include increasing brand awareness, brand liking, promoting customer engagement and loyalty, inspiring consumer word-of-mouth communication, potentially driving traffic to brand websites (Ashley and Tuten, 2015). Contrary to this, Mangold and Faulds (2009) and Hanna et al. (2011) both propose that in order to shape, influence and predict consumer conversations, marketing managers ought to engage with their audience emotionally. The TIWIS case shows that this can be achieved through designed activities on social media, for example, building communities, creating talking points such as 
memorable experiences or meaningful stories as opposed to simply posting HEI-branded content. Created stories should be consistent with the HEIs' integrated marketing communications strategy and should be inducted from student-to-student conversations to ensure authenticity and uniqueness of the content (Hanna et al., 2011).

This study demonstrates the value in HEIs adopting market-driven business practices and attempting to listen to and leverage student-generated social media content. However, the power of content creators needs to be left or shifted to students, whereas the role of HE marketers, educators and other stakeholders is in listening and engaging via students as brand personas, students who truly believe in a specific HEI brand but also are able to generate authentic stories and conversations with current and prospective students.

A number of studies (Kaplan and Haelein 2010; Kietzmann et al. 2011; Hanna et al. 2011;Chaffey and Smith 2013) have provided advice for utilising social media in a more effective manner. However, they only discuss implications and application in the corporate business context. HE context presents challenging environment with ongoing debate around whether students should be considered consumers of HE services and products. Despite the fact that pedagogical implications of the student-as-consumer approach are still to be examined, students do behave as consumers when choosing and even when experiencing HE beyond curriculum. We argue that when marketing HE and HEIs, learning from corporate brands and marketing communications practices is essential. HE context, however, creates opportunities for innovative ways of leveraging social media data, publicly available and generated by consumers. Engagements underpinned by emotional and authentic storytelling, tapping into the needs and desires of current and prospective students, ought to be main drivers behind HE marketing campaigns. 
Overall, although not directly proving the link between engagement with student-generated data and HE choices, the TIWIS case illustrates that student-generated data is an authentic source of data needed for the effective recruitment of international students. Further research is needed to examine the link. Moreover, this study triggers further exploration into ethics of adapting market-driven social media marketing practices by HEIs. As Scullion and Molesworth (2016) argue, students may not see themselves as consumers and, hence, see HEIs practices of 'watching' students in their personal spaces as invasion of their privacy.

\section{Acknowledgements}

We would love to thank Bournemouth University for initiating and supporting the TIWIS project and Dr Chindu Sreedharan for leading the TIWIS project and journalism student teams.

\section{References}

Adnan, H. (2014). An Analysis of the Factors Affecting Online Purchasing Behavior of Pakistani Consumers. International Journal of Marketing Studies, 6(5), 133. doi:10.5539/ijms.v6n5p133

Alwi, S. F. S., \& Kitchen, P. J. (2014). Projecting corporate brand image and behavioral response in business schools: Cognitive or affective brand attributes?. Journal of Business Research, 67(11), 2324-2336. doi: 10.1016/j.jbusres.2014.06.020

Ashley, C., \& Tuten, T. (2015). Creative strategies in social media marketing: An exploratory study of branded social content and consumer engagement. Psychology \& Marketing, 32(1), 1527. doi:10.1002/mar.20761 
Baird, D. E., \& Fisher, M. (2005). Neomillennial user experience design strategies: Utilizing social networking media to support "always on" learning styles. Journal of educational technology systems, 34(1), 5-32. doi:10.2190/6WMW-47L0M81Q-12G1

Barn, S. S. (2016). 'Tweet dreams are made of this, who are we to disagree?' Adventures in a \#Brave New World of \#tweets, \#Twitter, \#student engagement and \#excitement with \#learning. Journal of Marketing Management, 32(9-10), 1-22. doi:10.1080/0267257X.2016.1159598

Barczyk, C. C. \& Duncan, D. G. (2013). Facebook in higher education courses: An analysis of students' attitudes, community of practice, and classroom community. International Business and Management, 6(1), 1-11. doi:10.3968/j.ibm.1923842820130601.1165

Berger, J. \& Milkman, K. L. (2012). What makes online content viral? Journal of marketing research, 49(2), 192-205. doi:10.1509/jmr.10.0353

Brodie, R. J., Ilic, A., Juric, B. \& Hollebeek, L. (2013). Consumer engagement in a virtual brand community: An exploratory analysis. Journal of Business Research, 66(1), 105-114. doi:10.1016/j.jbusres.2011.07.029

Bunce, L., Baird, A. \& Jones, S.E. (2016). The student-as-consumer approach in higher education and its effects on academic performance. Studies in Higher Education, pp.1-21. doi:10.1080/03075079.2015.1127908

Calder, B. J., Malthouse, E. C. \& Maslowska, E. (2016). Brand marketing, big data and social innovation as future research directions for engagement. Journal of Marketing Management, 32(5-6), 579-585. doi:10.1080/0267257X.2016.1144326 
Chae, B. K. (2015). Insights from hashtag \#supplychain and Twitter Analytics: Considering Twitter and Twitter data for supply chain practice and research. International Journal of Production Economics, 165, 247-259. doi:10.1016/j.ijpe.2014.12.037

Chapleo, C. (2007). Barriers to brand building in UK universities? International Journal of Nonprofit \& Voluntary Sector Marketing, 12(1), 23-32. doi:10.1002/nvsm.271

Chevalier, J. A. \& Mayzlin, D. (2006). The effect of word of mouth on sales: Online book reviews. Journal of Marketing Research, 43(3), 345-354. doi:10.1509/jmkr.43.3.345

Clemes, M. D., Gan, C., \& Zhang, J. (2014). An empirical analysis of online shopping adoption in Beijing, China. Journal of Retailing and Consumer Services, 21(3), 364-375. doi:10.1016/j.jretconser.2013.08.003

Creswell, J.W. (2007). Qualitative inquiry and research design: Choosing among five approaches. Sage, $2^{\text {nd }}$ ed.

Dabbagh, N. \& Kitsantas, A. (2012). Personal Learning Environments, social media, and selfregulated learning: A natural formula for connecting formal and informal learning. The Internet and higher education, 15(1), 3-8. doi:10.1016/j.iheduc.2011.06.002

Dabbagh, N., Kitsantas, A., Al-Freih, M. \& Fake, H. (2015). Using social media to develop personal learning environments and self-regulated learning skills: a case study. International Journal of Social Media and Interactive Learning Environments, 3(3), 163-183. doi:10.1504/IJSMILE.2015.072300 
Deng, L., \& Tavares, N. J. (2013). From Moodle to Facebook: Exploring students' motivation and experiences in online communities. Computers \& Education, 68, 167-176. doi:10.1016/j.compedu.2013.04.028

Doorn, J. V., Verhoef, P.C., Lemon, K.N., Mittal, V., Nass, S., Pick, D. \& Pirner, P. (2010). Customer engagement behavior: Theoretical foundations and research directions. Journal of Service Research, 13(3), 253-266. doi:10.1177/1094670510375599

Eveland, W. (2003). A “Mix of Attributes” Approach to the Study of Media Effects and New Communication Technologies. Journal of Communication, 395-410. doi:10.1111/j.14602466.2003.tb02598.x

Faust, W. \& Householder, S., 2009. Get Real and Prosper: Why Social Media Demands Authentic Brands. Design Management Review, 20(1), 45-51. doi:10.1111/j.19487169.2009.tb00224.x

Fereday, J., \& Muir-Cochrane, E. (2006). Demonstrating rigor using thematic analysis: A hybrid approach of inductive and deductive coding and theme development. International journal of qualitative methods, 5(1), 80-92. doi: $10.1177 / 160940690600500107$

Fournier, S. \& Avery, J. (2011). The uninvited brand. Business horizons, 54(3), 193-207. doi:10.1016/j.bushor.2011.01.001

Gai, L., Xu, C. \& Pelton, L. E. (2016). A netnographic analysis of prospective international students’ decision-making process: implications for institutional branding of American 
universities in the emerging markets. Journal of Marketing for Higher Education, 26(2), 181198. doi: $10.1080 / 08841241.2016 .1245233$

Gensler, S., Völckner, F., Liu-Thompkins, Y. \& Wiertz, C. (2013). Managing brands in the social media environment. Journal of Interactive Marketing, 27(4), 242-256. doi:10.1016/j.intmar.2013.09.004

Godes, D. \& Mayzlin, D. (2004). Using online conversations to study word-of-mouth communication. Marketing Science, 23(4), 545-560. doi:10.1287/mksc.1040.0071

Hanna, R., Rohm, A. \& Crittenden, V.L. (2011). We're all connected: The power of the social media ecosystem. Business Horizons, 54(3), 265-273. doi:10.1016/j.bushor.2011.01.007

He, H., Fang, X., \& Du, Y. (2015). Revenue Sharing Contract Design with Marketing Strategy Types of Suppliers. In LISS 2014 (pp. 275-280). Springer Berlin Heidelberg. doi:10.1007/978-3662-43871-8_42

Heinonen, K. (2011). Consumer activity in social media: Managerial approaches to consumers' social media behavior. Journal of Consumer Behaviour, 10(6), 356-364. doi:10.1002/cb.376

Hemsley-Brown, J., \& Oplatka, I. (2006). Universities in a competitive marketplace - a systematic review of the literature on higher education marketing. International Journal of Public Sector Management, 19(4), 316-338. doi:10.1108/09513550610669176

Hemsley-Brown, J. \& Goonawardana, S. (2007). Brand harmonization in the international higher education market. Journal of Business Research, 60, 942-948. doi:10.1016/j.jbusres.2007.01.019 
Hetz, P. R., Dawson, C. L. \& Cullen, T. A. (2015). Social media use and the fear of missing out (FoMO) while studying abroad. Journal of Research on Technology in Education, 47(4), 259272. doi: $\underline{10.1080 / 15391523.2015 .1080585}$

Hussain, I. (2012). A study to evaluate the social media trends among university students. Procedia-Social and Behavioral Sciences, 64, 639-645. doi: 10.1016/j.sbspro.2012.11.075

Jan, M. T., \& Ammari, D. (2016). Advertising online by educational institutions and students' reaction: a study of Malaysian Universities. Journal of Marketing for Higher Education, 26(2), 168-180. doi:10.1080/08841241.2016.1245232

Kaplan, A.M. \& Haenlein, M. (2010). Users of the world, unite! The challenges and opportunities of social media, Business Horizons, 53(1), 59-68.

doi:10.1016/j.bushor.2009.09.003

Khanna, M., Jacob, I. \& Yadav, N. (2014). Identifying and analyzing touchpoints for building a higher education brand. Journal of Marketing for Higher Education, 24(1), 122-143. doi: $\underline{10.1080 / 08841241.2014 .920460}$

Ko, H., Cho, C.H. \& Roberts, M.S. (2005). Internet uses and gratifications: a structural equation model of interactive advertising. Journal of Advertising, 34(2), 57-70. doi:10.1080/00913367.2005.10639191

Kietzmann, J. H., Hermkens, K., McCarthy, I. P., \& Silvestre, B. S. (2011). Social media? Get serious! Understanding the functional building blocks of social media. Business horizons, 54(3), 241-251. doi:10.1016/j.bushor.2011.01.005 
Kozinets, R. V. (2015). Netnography redefined. John Wiley \& Sons, Inc.

Kozinets, R., Wojnicki, A. C., Wilner, S. J., \& De Valck, K. (2010). Networked narratives: Understanding word-of-mouth marketing in online communities. Journal of Marketing, 74(2), 71-89. doi:10.1509/jmkg.74.2.71

Krishnamurthy, S., \& Dou, W. (2008). Note from special issue editors: Advertising with usergenerated content: A framework and research agenda. Journal of Interactive Advertising, 8(2), 14. doi: $\underline{10.1080 / 15252019.2008 .10722137}$

Langer, R. \& Beckman, S.C. (2005). Sensitive research topics: netnography revisited. Qualitative Market Research: An International Journal, 8(2), 189 - 203. doi: $\underline{10.1108 / 13522750510592454}$

Legislation.gov.uk, 2000. Race Relations (Amendment) Act 2000. [online]. http://www.legislation.gov.uk/ukpga/2000/34/pdfs/ukpga_20000034_en.pdf [Accessed 22 Dec. 2015].

Malthouse, E. C., Calder, B. J., Kim, S. J. \& Vandenbosch, M. (2016). Evidence that usergenerated content that produces engagement increases purchase behaviours. Journal of Marketing Management, 32(5-6), 427-444. doi:10.1080/0267257X.2016.1148066

Mangold, G. \& Faulds, D. (2009). Social Media: The new hybrid element of the promotion mix. Business Horizons, 52(4), 357-365. doi:10.1016/j.bushor.2009.03.002 
Molesworth, M., Nixon, E. \& Scullion, R. (2009). Having, being and higher education: The marketisation of the university and the transformation of the student into consumer. Teaching in higher Education, 14(3), 277-287. doi:10.1080/13562510902898841

Muntinga, D. G., Moorman, M. \& Smit, E. G. (2011). Introducing COBRAs: Exploring motivations for brand-related social media use. International Journal of Advertising, 30(1), 1346. doi:10.2501/IJA-30-1-013-046

Murdough, C. (2009). Social media measurement: It’s not impossible. Journal of Interactive Advertising, 10, 94-99. doi:10.1080/15252019.2009.10722165

Ngai, E. W., Tao, S. S., \& Moon, K. K. (2015). Social media research: Theories, constructs, and conceptual frameworks. International Journal of Information Management, 35(1), 33-44. doi:10.1016/j.ijinfomgt.2014.09.004

Nel, L. (2015). Technological utopia, dystopia and ambivalence: Teaching with social media at a South African university. British Journal of Educational Technology, 46(3), 629-648. doi:10.1111/bjet.12159

Neier, S. \& Zayer, L.T. (2015). Students’ perceptions and experiences of social media in higher education. Journal of Marketing Education, 37(3), 133-143. doi:10.1177/0273475315583748

Nixon, E., Scullion, R. \& Hearn, R. (2016). Her majesty the student: marketised higher education and the narcissistic (dis) satisfactions of the student-consumer. Studies in Higher Education, 121. doi:10.1080/03075079.2016.1196353 
Oakes, S., Dennis, N., \& Oakes, H. (2013). Web-based forums and metaphysical branding. Journal of Marketing Management, 29(5-6), 607-624. doi:10.1080/0267257X.2013.774289

Pang, B. \& Lee, L. (2008). Opinion Mining and Sentiment Analysis. Foundations and Trends in Information Retrieval, 2(1-2), 1-135. doi:10.1561/1500000011

Pringle, M. (1993). Change and Teamwork in Primary Care. British Medical Journal Publishing Co.

Punj, G. (2011). Effect of Consumer Beliefs on Online Purchase Behavior: The Influence of Demographic Characteristics and Consumption Values. Journal of Interactive Marketing, 25(3), 134-144. doi:10.1016/j.intmar.2011.04.004

Royo-Vela, M. \& Hünermund, U. (2016). Effects of inbound marketing communications on HEIs' brand equity: the mediating role of the student's decision-making process. An exploratory research. Journal of Marketing for Higher Education, 26(2), 143-167. doi: $\underline{10.1080 / 08841241.2016 .1233165}$

Scullion, R. \& Molesworth, M. (2016). Normalisation of and resistance to consumer behaviour in higher education. Journal of Marketing for Higher Education, 26(2), 129-131. doi: $10.1080 / 08841241.2016 .1248104$

Singh, S. \& Sonnenburg, S. (2012). Brand performances in social media. Journal of Interactive Marketing, 26(4), 189-197. doi:10.1016/j.intmar.2012.04.001

Smith, N., Wollan, R. \& Zhou, C. (2011). The Social Media Management Handbook: Everything You Need to Know to Get Social Media Working in Your Business. Hoboken, N.J.: Wiley. 
Strekalova, Y. A. \& Krieger, J. L. (2015). A picture really is worth a thousand words: Public engagement with the National Cancer Institute on social media. Journal of Cancer Education, 13. doi:10.1007/s13187-015-0901-5

Tomlinson, M. (2015). Student perceptions of themselves as ‘consumers' of higher education. British Journal of Sociology of Education, 1-15. doi:10.1080/01425692.2015.1113856

Tuten, T. \& Solomon, M. (2014). Social Media Marketing. Harlow: Pearson.

Vaidehi, P. (2014). Factors influencing online shopping behavior of students in engineering colleges at Rangareddy district. Sumedha Journal of Management, 3(1), pp.50-62. http://nsuworks.nova.edu/tqr/vol21/iss1/1

Veletsianos, G., Collier, A. \& Schneider, E. (2015). Digging deeper into learners' experiences in MOOCs: Participation in social networks outside of MOOCs, notetaking and contexts surrounding content consumption. British Journal of Educational Technology, 46(3), 570-587. doi: 10.1111/bjet.12297

Vorderer, P., Krömer, N. \& Schneider, F. M. (2016). Permanently online-Permanently connected: Explorations into university students' use of social media and mobile smart devices. Computers in Human Behavior, 63, 694-703. doi: $\underline{10.1016 / j . c h b .2016 .05 .085}$

Whelan, S. \& Wohlfeil, M. (2006). Communicating brands through engagement with 'lived' experiences. Journal of Brand Management, 13(4/5), 313-329.

doi:10.1057/palgrave.bm.2540274 
Whiting, A. \& Williams, D. (2013). Why people use social media: a uses and gratifications approach. Qualitative Market Research: An International Journal, 16(4), 362 - 369. doi:10.1108/QMR-06-2013-0041

\section{Author Biographies}

Dr Elvira Bolat is a Senior Lecturer in Marketing at the Faculty of Management, Bournemouth University. Her teaching covers courses on both undergraduate and postgraduate levels. Her research interests cover a digitisation of small and medium sized firms and its effect on service innovations practices as well as digital transformation of learning and higher education. She has an extensive track record in working on digital marketing in the Business to Business (B2B) Marketing research area, hence, Elvira is the acting Deputy Chair for the Academy of Marketing B2B Special Interest Group.

Helen O'Sullivan is a Lecturer in Marketing at Bournemouth University. After working as a broadcast journalist in Australia and the U.K., she moved into the HE sector where she worked for nine years as a marketing manager and head of school liaison. She has retained her interest in the sector as an academic, where the main focus of her research is branding in higher education, with particular focus on UK post-92 universities. 